\title{
An outbreak of HCV genotype 6a and 2a infection in South China: Confirmation of iatrogenic transmission by phylogenetic analysis of the NS5B region
}

\author{
XIAOQIONG SHAO $^{1 *}$, QIUMIN LUO $^{1 *}$, QINGXIAN CAI $^{*}{ }^{*}$, FULONG ZHANG $^{2}$, JIANGYUN ZHU ${ }^{1}$, \\ YING LIU $^{1}$, ZHIXIN ZHAO ${ }^{1}$, ZHILIANG GAO ${ }^{1}$ and XIAOHONG ZHANG ${ }^{1}$
}

${ }^{1}$ Department of Infectious Disease, The Third Affiliated Hospital of Sun Yat-Sen University, Guangzhou, Guangdong 510630;

${ }^{2}$ Department of Internal Medicine, Zijin County People's Hospital, Heyuan, Guangdong 517400, P.R. China

Received August 31, 2015; Accepted September 2, 2016

DOI: $10.3892 / \mathrm{mmr} .2016 .5737$

\begin{abstract}
An outbreak of hepatitis C virus (HCV) infections, for which the risk factor was unknown, was previously identified in North Guangdong, China. In the present study, a total of 736 local residents were surveyed regarding their lifetime risk factors for $\mathrm{HCV}$ infection. Serum anti-HCV antibodies and HCV RNA were examined to confirm infection. In the $\mathrm{HCV}$-positive samples, the core and nonstructural protein $5 \mathrm{~B}$ sequences were amplified, and phylogenetic analysis was performed to determine the association between $\mathrm{HCV}$ subtypes and transmission routes. A total of 374 individuals were positive for anti-HCV antibodies. Blood transfusion, blood product transfusion, people who inject drugs and intravenous injection at a local clinic were identified as independent risk factors for $\mathrm{HCV}$ infection. Phylogenetic analysis revealed that the two predominant subtypes of $\mathrm{HCV}, 2 \mathrm{a}$ and $6 \mathrm{a}$, were primarily focused in four homologous clusters. Patients with a history of intravenous injection at a local clinic were more likely to be found in the four clusters, compared with patients exposed to other risk factors. The present emergency retrospective survey showed a specific epidemiological feature of HCV infection in Zijin County and found genetic homology among individuals exposed to intravenous injection at a local clinic. Further evidence is required to confirm the causal association between the outbreak of HCV infection and intravenous injection.
\end{abstract}

Correspondence to: Dr Qingxian Cai, Department of Infectious Disease, The Third Affiliated Hospital of Sun Yat-Sen University, 600 Tianhe Road, Tianhe, Guangzhou, Guangdong 510630, P.R. China

E-mail: kaishiao@163.com

*Contributed equally

Key words: intravenous injection, glass syringe, hepatits C virus, genotyping, phylogenetic analysis

\section{Introduction}

Hepatitis $\mathrm{C}$ virus (HCV) infection is one of the primary causes of chronic liver disease worldwide (1). It is estimated that $3 \%$ of the world's population is chronically infected with HCV (2), although the frequency of infection varies between populations and geographic regions (3). In Western Europe, the prevalence of HCV ranges between 0.4 and 3\%. In Eastern Europe and the Middle East, the prevalence is higher, although the exact prevalence remains to be fully elucidated (4). The highest worldwide prevalence is in Egypt, which has a national prevalence of $9 \%$ and a prevalence of up to $50 \%$ in rural areas (5).

$\mathrm{HCV}$ is transmitted parenterally. Prior to the 1990s, the principal routes of $\mathrm{HCV}$ transmission were blood transfusion, intravenous drug use and unsafe injection procedures (6). In industrialized countries, these modes of transmission account for $\sim 70 \%$ of HCV infections (6). Since 1992, screening of blood donors has essentially eradicated the transmission of HCV by transfusion. Currently, new HCV infections are caused by intravenous or nasal drug use and, to a lesser degree, unsafe medical or surgical procedures (7). Sexual transmission of $\mathrm{HCV}$ among men who have intercourse with men was also a major route of transmission, and data indicates that promiscuous male homosexual activity is associated with HCV infection (8).

China has a population of $1,300,000,000$; the frequency of $\mathrm{HCV}$ infection has been reported to be $3.2 \%$ nationally and $3.1 \%$ in rural areas $(9,10)$. However, the prevalence of $\mathrm{HCV}$ infection differs between regions (11). The transmission of HCV via contaminated blood was previously a serious issue in China. Between 1994 and 1996, a plasma campaign in Henan province resulted in the infection of 500,000 blood donors with $\mathrm{HCV}$ and the infection of 300,000 donors with human immunodeficiency virus (12-15). Similar experiences were also reported in other provinces of China (14).

At present in China (since 1992), the principal routes of transmission for newly diagnosed $\mathrm{HCV}$ infections are blood transfusions, surgical procedures and intravenous drug use $(16,17)$.

Guangdong is a province on the South China Sea coast of China. A previous study from a medical center in Guangdong 
province sampled 393 patients with chronic hepatitis $\mathrm{C}$ and showed that the predominant HCV subtypes were subtypes $1 \mathrm{~b}$, $6 \mathrm{a}, 2 \mathrm{a}, 3 \mathrm{a}$ and $3 \mathrm{~b}$, which accounted for $65.9,17.1,7.4,3.6$ and $3.3 \%$ of cases, respectively (18).

Zijin County is located in the north of Guangdong province and has a population of $\sim 800,000$. The present study focussed on a previous outbreak in which dozens of cases of $\mathrm{HCV}$ infection were newly diagnosed in the same local street. It did not appear that the principle routes of HCV transmission, including blood transfusion or intravenous drug use, were responsible for this outbreak. To determine the transmission routes of this specific outbreak, the present study conducted an emergency survey of the region.

\section{Materials and methods}

Study design. In late February 2012, an emergency survey was conducted investigate the HCV epidemic of Xiangshui Road in Zijin County, Heyuan. A questionnaire regarding lifetime risk factors for $\mathrm{HCV}$ infection was administered to all local residents. Blood samples were obtained from all respondents $(n=736)$ and the serum was separated from the samples by centrifugation $\left(2,200 \times \mathrm{g}, 10 \mathrm{~min}, 4^{\circ} \mathrm{C}\right)$. Healthcare workers from a recently closed local medical clinic were interviewed regarding procedures at the clinic. Informed consent was obtained from all participants. The present study was performed in accordance with the 1964 Declaration of Helsinki and later amendments. The protocol was approved by the ethics committee of the Third Affiliated Hospital of Sun Yat-Sen University (Guangzhou, China).

\section{Analysis of serum samples}

Determination of HCV infection. An HCV enzyme immunoassay (HCV EIA 3.0; Abbott GmbH, Wiesbaden, Germany) was used to detect anti-HCV antibodies in the serum samples. Individuals positive for anti-HCV antibodies were further assessed for the presence of HCV RNA using the COBAS AMPLICOR HCV Monitor 2.0 assay (Roche Diagnostics, Branchburg, NJ, USA). If the result was negative, a second serum sample was acquired from the respondents for analysis 1 month following the initial sample analysis.

Sequencing of HCV RNA. The HCV RNA was extracted from serum samples identified as positive for HCV RNA. HCV RNA sequencing was performed as described previously (19). In brief, the HCV RNA was extracted from the serum samples using the RNAiso ${ }^{\mathrm{TM}}$ Plus extraction kit (Takara Biotechnologoy Co., Ltd., Dalian, China). The HCV RNA was then reverse transcribed into cDNA using the ReverTra Ace- $\alpha$-reverse transcription kit (Toyobo, Shanghai, China), according to the manufacturer's protocol. The core and nonstructural protein 5B (NS5B) regions of the $\mathrm{HCV}$ were amplified using a nested polymerase chain reaction. The core outer primers were as follows: Forward, 5'-ACTGCCTGATAGGGTGCTTGC-3' and reverse, 5'-ATGTACCCCATGAGGTCGGC-3'; the inner primers were: Forward,5'-AGGTCTCGTAGACCGTGCA-3' and reverse, 5'-CATGTGAGGGTATCGATGAC-3'. The NS5B outer degenerate primers were: Forward, $5^{\prime}$ - CCACATCMRCTCCGTGTGTGG-3' and reverse, 5'-GGRGCDGARTACCTRGTCAT-3'; the inner degenerate primers were: Forward, 5'-ACMCCAATWSMCACBACCATCATG-3' and reverse, 5'-TACCTGGTCATAGCCTCCGTGA-3'. PCR was conducted using the Takara Taq ${ }^{\mathrm{TM}}$ PCR kit (Takara Biotechnologoy Co., Ltd.). The outer PCR system $(30 \mu \mathrm{l})$ consisted of: $3 \mu \mathrm{l}$ 10X PCR

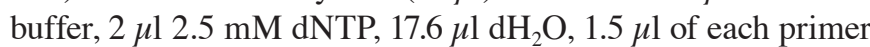
(10 pmol/ $/ \mu \mathrm{l}), 0.4 \mu \mathrm{l}$ Taq enzyme $(2.5 \mathrm{U} / \mu \mathrm{l})$ and $4 \mu \mathrm{l}$ template cDNA. Inner PCR system (30 $\mu \mathrm{l})$ consisted of: $3 \mu \mathrm{l} 10 \mathrm{X}$ PCR

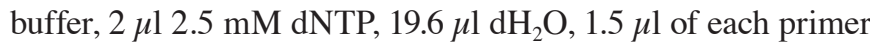
(10 pmol $/ \mu \mathrm{l}), 0.4 \mu \mathrm{l} \mathrm{Taq}$ enzyme $(2.5 \mathrm{U} / \mu \mathrm{l})$ and $2 \mu \mathrm{l}$ template cDNA. PCR conditions were as follows: $94^{\circ} \mathrm{C}$ for $5 \mathrm{~min}$; followed by 30 cycles at $94^{\circ} \mathrm{C}$ for $30 \mathrm{sec}, 55^{\circ} \mathrm{C}$ for $1 \mathrm{~min}$ and $72^{\circ} \mathrm{C}$ for $40 \mathrm{sec}$; and a final step at $72^{\circ} \mathrm{C}$ for $10 \mathrm{~min}$. DNA was sequenced in both directions using an ABI Prism 3,730 genetic analyzer (Applied Biosystems; Thermo Fisher Scientific, Inc., Waltham, MA, USA). The experiment was performed twice, at an interval of 2 months, to confirm the results.

Phylogenetic analysis of core and NS5B alignments. The sequences of the HCV strains were aligned using the ClustalW 1.8 software package (20), with a reference panel of sequences representative of each subtype (21) retrieved from the HCV database (http://hcv.lanl.gov/content/index). Prior to phylogenetic analysis, the jModeltest program (22) was used to determine the optimal substitution model based on the Akaike information criterion (23). The results indicated that $\mathrm{K} 2+\mathrm{G}$ was the optimal model for the Core-E1 and NS5B datasets. Under this model, maximum-likelihood trees were estimated using the subtree pruning and regrafting and nearest neighbor interchange algorithms in PhyML (24). Bootstrap support values (1,000 repetitions) of $>70 \%$ were accepted as defining clusters.

Statistical analysis. Differences between groups were examined using a $\chi^{2}$ test. To identify the factors significantly associated with $\mathrm{HCV}$ infection, univariate logistic regression analysis was performed, and the variables with $\mathrm{P}<0.15$ in univariable analysis were selected for multiple binary logistic regression analyses with backwards elimination forced in the final model. Statistical analysis was performed using SPSS version 19.0 (IBM SPSS, Armonk, NY, USA). P<0.05 was considered to indicate a statistically significant difference.

\section{Results}

HCV infection and risk factors. A total of 736 residents from Xiangshui Road, Zijin, Guangdong, were included in the survey. The included residents had an average age of $40.3 \pm 19.6$ years old (range, 4-90 years old) and $51.4 \%$ were men $(378 / 736$ respondents). Of the 736 residents included in the survey, $50.8 \%$ were positive for the anti-HCV antibody. The characteristics of the $\mathrm{HCV}$-positive and $\mathrm{HCV}$-negative survey respondents are shown in Table I.

Using univariate logistic regression analysis, the exposure of an individual to a number of risk factors, including blood product transfusion, intravenous injection at a local clinic and $\geq 2$ infected family members, were significantly associated with the risk of HCV infection. Gender, age, HBV surface antigen (HBsAg), blood donor history, blood transfusion history, intravenous drug use, surgery history, dental visit history and number of sexual partners were not significantly associated 
Table I. Univariate and multivariate logistic regression analyses of risk factors associated with HCV infection.

\begin{tabular}{|c|c|c|c|c|c|c|}
\hline $\begin{array}{l}\text { Characteristics } \\
\text { and risk factors }\end{array}$ & $\begin{array}{l}\text { HCV positive } \\
\quad(n=374)\end{array}$ & $\begin{array}{l}\text { HCV negative } \\
\quad(n=362)\end{array}$ & $\begin{array}{l}\text { Crude OR } \\
(95 \% \mathrm{CI})\end{array}$ & P-value & $\begin{array}{l}\text { Adjusted OR } \\
\quad(95 \% \mathrm{CI})\end{array}$ & P-value \\
\hline Male & $182(48.7 \%)$ & $193(53.3 \%)$ & $0.83(0.62-1.11)$ & 0.207 & & \\
\hline Age ( $\geq 40$ years old) & $205(54.8 \%)$ & $184(50.8 \%)$ & $1.17(0.88-1.57)$ & 0.279 & $1.37(0.94-1.99)$ & 0.100 \\
\hline $\mathrm{HBsAg}$ & $28(7.5 \%)$ & $29(8.0 \%)$ & $0.93(0.54-1.60)$ & 0.790 & & \\
\hline Blood donor & $19(5.1 \%)$ & $23(6.4 \%)$ & $0.79(0.42-1.48)$ & 0.457 & & \\
\hline Blood transfusion & $22(5.9 \%)$ & $12(3.3 \%)$ & $1.82(0.89-3.7)$ & 0.097 & $9.14(4.04-20.67)$ & $<0.001$ \\
\hline Blood product & $45(12.0 \%)$ & $27(7.5 \%)$ & $1.70(1.03-2.80)$ & 0.037 & $2.99(1.54-5.78)$ & 0.001 \\
\hline Drug use (injection) & $14(3.7 \%)$ & $7(1.9 \%)$ & $1.97(0.79-4.94)$ & 0.140 & $14.98(5.52-40.64)$ & $<0.001$ \\
\hline Surgery history & $28(7.5 \%)$ & $34(9.4 \%)$ & $0.78(0.46-1.32)$ & 0.352 & & \\
\hline Intravenous injection $^{a}$ & $303(81.0 \%)$ & $93(25.7 \%)$ & $12.34(8.70-17.51)$ & $<0.001$ & $20.63(13.64-31.21)$ & $<0.001$ \\
\hline Visited a dentist & $36(9.6 \%)$ & $32(8.8 \%)$ & $1.10(0.67-1.81)$ & 0.713 & & \\
\hline Family infection ${ }^{\mathrm{b}}$ & $98(26.2 \%)$ & $55(15.2 \%)$ & $1.98(1.37-2.86)$ & $<0.001$ & & \\
\hline Sexual history ${ }^{\mathrm{c}}$ & $14(3.7 \%)$ & $11(3.0 \%)$ & $1.24(0.56-2.77)$ & 0.598 & & \\
\hline
\end{tabular}

Respondents were defined as HCV positive if samples were positive for anti-HCV antibodies or the presence of HCV RNA. Variables selected in the final model were determined by backwards stepwise elimination. ${ }^{a}$ Respondents received intravenous injection from a clinic in which

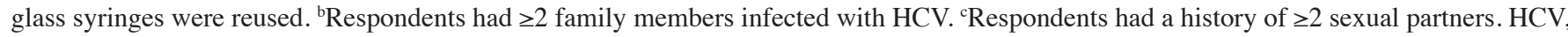
hepatitis C virus; OR, odds ratio; CI, confidence interval; $\mathrm{HBsAg}$, hepatitis B virus surface antigen.

Table II. Univariate and multivariate logistic regression analyses of risk factors associated with a positive HCV result.

\begin{tabular}{|c|c|c|c|c|c|c|}
\hline $\begin{array}{l}\text { Characteristics } \\
\text { and risk factors }\end{array}$ & $\begin{array}{l}\text { HCV RNA }(+) \\
(n=264) n(\%)\end{array}$ & $\begin{array}{l}\text { HCV RNA }(-) \\
(n=110) \text { n }(\%)\end{array}$ & $\begin{array}{l}\text { Crude OR } \\
(95 \% \mathrm{CI})\end{array}$ & P-value & $\begin{array}{l}\text { Adjusted OR } \\
(95 \% \mathrm{CI})\end{array}$ & P-value \\
\hline Male & $126(47.7)$ & $56(50.9)$ & $0.88(0.56-1.37)$ & 0.575 & & \\
\hline Age ( $\geq 40$ years old) & $156(59.1)$ & $44(40.0)$ & $3.42(2.07-5.65)$ & $<0.001$ & $2.24(1.38-3.64)$ & 0.001 \\
\hline HBsAg & $20(7.6)$ & $8(7.3)$ & $1.05(0.45-2.45)$ & 0.919 & & \\
\hline Blood transfusion & $15(5.7)$ & $7(6.4)$ & $0.89(0.35-2.24)$ & 0.798 & $0.89(0.30-2.61)$ & 0.832 \\
\hline Blood product & $29(11.0)$ & $16(14.5)$ & $0.73(0.38-1.40)$ & 0.335 & $0.68(0.35-1.34)$ & 0.265 \\
\hline Drug use (injection) & $9(3.4)$ & $8(7.3)$ & $0.45(0.17-1.20)$ & 0.102 & $0.64(0.173-2.37)$ & 0.504 \\
\hline Intravenous injection $^{\mathrm{a}}$ & $225(85.2)$ & $78(70.9)$ & $2.37(1.39-4.04)$ & 0.001 & $1.64(0.80-3.37)$ & 0.177 \\
\hline
\end{tabular}

Respondents were defined as HCV RNA positive if samples were positive for HCV RNA. Gender, age, HBsAg status and associated risk factors (Table I) were selected as variables in the multivariate logistic regression analyses. ${ }^{a}$ Respondents received intravenous injection from a clinic in which glass syringes were reused. HCV, hepatitis C virus; OR, odds ratio; CI, confidence interval; HBsAg, hepatitis B virus surface antigen.

with the risk of $\mathrm{HCV}$ infection. Of the infected patients, $86.6 \%$ (324/374) had multiple risk factors, and $86.7 \%(85 / 98)$ of the individuals with $\geq 2$ family members infected with HCV had a history of intravenous injection at a local clinic. To further examine the association between risk factors and HCV infection, multivariate logistic regression analysis was performed (Table II). Following adjustment for blood transfusions, blood product transfusion, intravenous drug use and intravenous injection, the number of family members infected with $\mathrm{HCV}$ was not a significant risk factor for $\mathrm{HCV}$ infection.

A total of $53.8 \%(396 / 736)$ of the survey respondents indicated a history of visiting a local clinic where they had received intravenous injection. The clinic had closed 3 months prior to the initiation of the survey. When the healthcare workers from the closed clinic were interviewed, they stated that they had reused glass syringes for intravenous injections and that equipment was cleaned through scalding. Following each injection, the needle and syringe were washed by filling it with clean water several times and shaking vigorously for $30 \mathrm{sec}$. This cleaning process was repeated twice. The syringe was later detached from the needle and boiled for 15 min with $2 \%$ sodium carbonate for $15 \mathrm{~min}$. However, this procedure was not always observed by the survey respondents, particularly when there were numerous patients attending the clinic.

Positivity for HCV RNA. The 374 respondents who were positive for anti-HCV antibodies were examined for the presence of HCV RNA using reverse transcription-polymerase chain reaction analysis. The results showed that $264(70.5 \%)$ were positive for HCV RNA. 


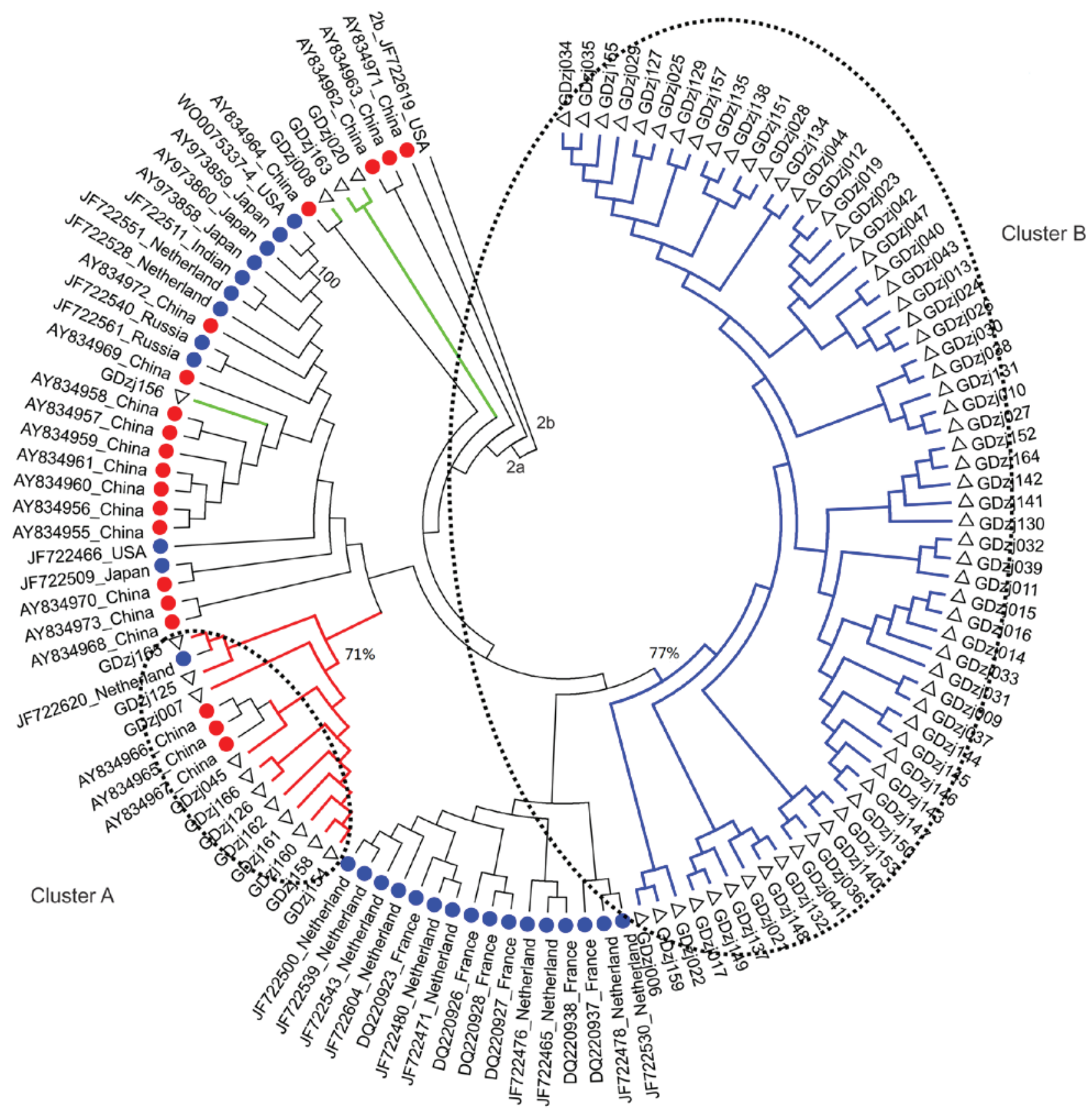

Figure 1. Categorization of cases of HCV by suspected risk factor. Two clusters of HCV subtype 2a were identified in the survey respondents. The HCV subtype 2a phylogeny was estimated from the NS5B, nonstructural protein 5B region sequences. The HCV subtype $2 \mathrm{~b}$ sequence was included as a negative control. Blue circles indicate HCV reference sequences from outside China; red circles are indicative of HCV reference sequences from other studies in China (origin country and accession numbers in GenBank are shown). Sequences with triangles are unique to the present study (Genbank accession nos. KJ416703-KJ416924). Sequences connected by blue and red lines, surrounded by the black dashed circles are indicative of cluster A (11 cases) and cluster B (63 cases). Sequences connected by green lines are indicative of sequences not in cluster A or B (four cases). Bootstrap support values are shown as percentages. $\mathrm{HCV}$, hepatitis $\mathrm{C}$ virus.

In the HCV RNA-positive survey respondents, only age was significantly associated with the risk of being HCV RNA positive (odds ratio, 2.22; 95\% confidence interval, 1.41-3.50; $\mathrm{P}<0.001)$. In the multivariate logistic regression analysis, having $\geq 2$ sexual partners, or exposure to intravenous injection, intravenous drug use, blood product transfusion or blood transfusion were not found to be significantly associated with the risk of a positive HCV RNA result.

HCV subtype and phylogenetic grouping. RNA was extracted from the serum of the survey respondents identified as positive for the presence of HCV RNA (264 samples). Core and NS5B sequences were amplified successfully in 237 and 222 cases, respectively. Core and NS5B sequences were obtained in 213 respondents, core sequences were obtained in 24 respondents and NS5B sequences were obtained in nine respondents. Together, the amplification of either or both sequence regions was successful in 246 cases.

A total of four HCV subtypes were identified in the HCV RNA-positive samples: Subtype $1 \mathrm{~b}$ in nine $(3.7 \%)$ cases, subtype 2a in $84(34.1 \%)$ cases, subtype $3 b$ in two (0.8\%) cases and subtype 6a in $151(61.4 \%)$ cases. The genotypes 
Table III. Hepatitis C virus subtype distribution by risk factor.

\begin{tabular}{|c|c|c|c|c|c|}
\hline \multirow[b]{2}{*}{ Risk factor } & \multicolumn{2}{|c|}{ Subtype $2 \mathrm{a}$} & \multicolumn{2}{|c|}{ Subtype $6 a$} & \multirow[b]{2}{*}{ Remaining group } \\
\hline & Cluster A & Cluster B & Cluster C & Cluster D & \\
\hline Other risk factors ${ }^{\mathrm{a}}$ & 1 & 4 & 2 & 6 & 1 \\
\hline Blood transfusion & 0 & 2 & 1 & 1 & 7 \\
\hline Blood product transfusion & 0 & 1 & 1 & 1 & 3 \\
\hline Drug use (injection) & 0 & 0 & 2 & 1 & 2 \\
\hline Intravenous injection $^{\mathrm{b}}$ & 9 & 55 & 13 & 102 & 7 \\
\hline Total & 10 & 62 & 19 & 111 & 20 \\
\hline
\end{tabular}

Data are representative of cases in which nonstructural protein 5B was successfully amplified and phylogenetically analyzed. ${ }^{\mathrm{a}} \mathrm{Other}$ risk factors included blood donor history, surgery history, dental visit history and sexual history. ${ }^{\mathrm{b}}$ Intravenous injection at a local clinic.

determined by the core sequences were consistent with those determined by NS5B sequences.

$\mathrm{HCV}$ subtypes $2 \mathrm{a}$ and $6 \mathrm{a}$ were further analyzed through the generation of NS5B trees, since these subtypes accounted for $95.5 \%$ of genotypes confirmed. The NS5B sequences of subtype $2 \mathrm{a}$ were grouped into clusters A and B, which contained the sequences of 11 and 63 samples, respectively (Fig. 1). The bootstrap scores of clusters A and B were 71 and $77 \%$, respectively. The NS5B sequences of subtype $6 a$ were grouped into cluster $\mathrm{C}$ and $\mathrm{D}$, which contained the sequences of 20 and 112 samples, respectively (Fig. 2). The bootstrap scores of cluster C and D were 73 and $81 \%$, respectively. The patients exposed to intravenous injection were more likely to distribute in clusters $\mathrm{A}, \mathrm{B}, \mathrm{C}$ and $\mathrm{D}$, compared with those exposed to other risk factors $(179 / 186$, vs. $23 / 36$; $\mathrm{P}<0.001$; Table III).

\section{Discussion}

An outbreak of HCV infection was identified on a single road, Xiangshui Road, Zijin, Guangdong. Of the 736 respondents of the survey distributed to local residents, $50.8 \%$ were $\mathrm{HCV}$-seropositive. Analysis of the risk factors for $\mathrm{HCV}$ infection among the survey respondents found that blood transfusion, intravenous drug use and intravenous injection at a local clinic were associated with HCV infection. Phylogenetic analysis of HCV NS5B sequences identified four clusters, suggesting a common mode of transmission, with the majority of patients reporting injection at a local clinic. The present study hypothesized that transmission may have occurred through unsafe injection practices.

In the present study, blood donation, surgery, dental visits, and having $\geq 2$ sexual partners were not significantly associated with $\mathrm{HCV}$ infection. In China, paid blood donation has been banned since 1998, and HCV infection rates in blood donors have decreased from 12.87 to $1.71 \%(25,26)$. HCV screening prior to surgery has been routine practice since 1992, thus transmission of HCV via surgery or dental care is well controlled. It is known that sexual transmission of $\mathrm{HCV}$ accounts for $<5 \%$ of $\mathrm{HCV}$ infections (27), as HCV is rarely present in semen or vaginal fluid. The risk of HCV infection for an individual who is in an unprotected sexual relationship with an HCV-infected individual for 20 years is $2.5 \%$ (28). Although it has been reported that the prevalence of $\mathrm{HCV}$ infection in the intravenous drug use population was $61.4 \%$ in China (9), and the infection rate was substantially higher in southwestern China, only a marginal proportion of the survey respondents had a history of intravenous drug use (21/736). These results suggested that blood donation, surgery, dental visits and having $\geq 2$ sexual partners were not the primary routes of HCV transmission in the individuals in the present study.

The spontaneous clearance of HCV occurs in 15-30\% of cases of acute HCV (29) and is associated with interleukin $28 \mathrm{~B}$ gene variation $(30,31)$. The frequency of the rs12979860 C allele, which contributes to viral clearance in the Chinese Han population ranges between 74 and 98\% (32). Thus, it may be that $70.5 \%$ of the anti-HCV antibody-positive respondents who were HCV RNA-positive in the present study was a result of spontaneous clearance.

$\mathrm{HCV}$ has been classified into seven genotypes and 82 subtypes(http://talk.ictvonline.org/ictv_wikis/w/sg_flavi/35. table-1-confirmed-hcv-genotypessubtypes-november-2014. aspx). Genotypes differ from each other by $31-33 \%$ at the nucleotide level, whereas subtypes differ by 20-25\% (33). Despite the genetic diversity of $\mathrm{HCV}$, all genotypes share collinearity in the large open reading frame, and the genetic associations of $\mathrm{HCV}$ variants consistent throughout the genome (33). Through genotyping of the HCV core and NS5B sequences of the infected patients, the present study showed that the genotypes determined by core sequences were consistent with those determined by NS5B sequences.

HCV genotypes have varied geographic distribution patterns. HCV subtypes $1 \mathrm{a}, 1 \mathrm{~b}, 2 \mathrm{a}, 2 \mathrm{~b}$ and $3 \mathrm{a}$ are distributed globally, whereas all other subtypes are restricted predominantly to certain geographic regions. Genotype 6 and its subtypes are found predominantly in Southeast Asia (34). Studies in Southern China have reported that HCV-6a accounts for $49.7 \%$ of cases detected in blood donors and $17.1 \%$ in patients with chronic $\mathrm{HCV}$ infection, and its overall proportion is increasing $(35,36)$. In Guangdong, the predominant $\mathrm{HCV}$ subtypes in patients with chrnoic HCV are subtypes $1 \mathrm{~b}$, $6 \mathrm{a}, 2 \mathrm{a}, 3 \mathrm{a}$ and $3 \mathrm{~b}$ (18). However, the genotypic distribution in the present study, which predominantly consisted of genotype 


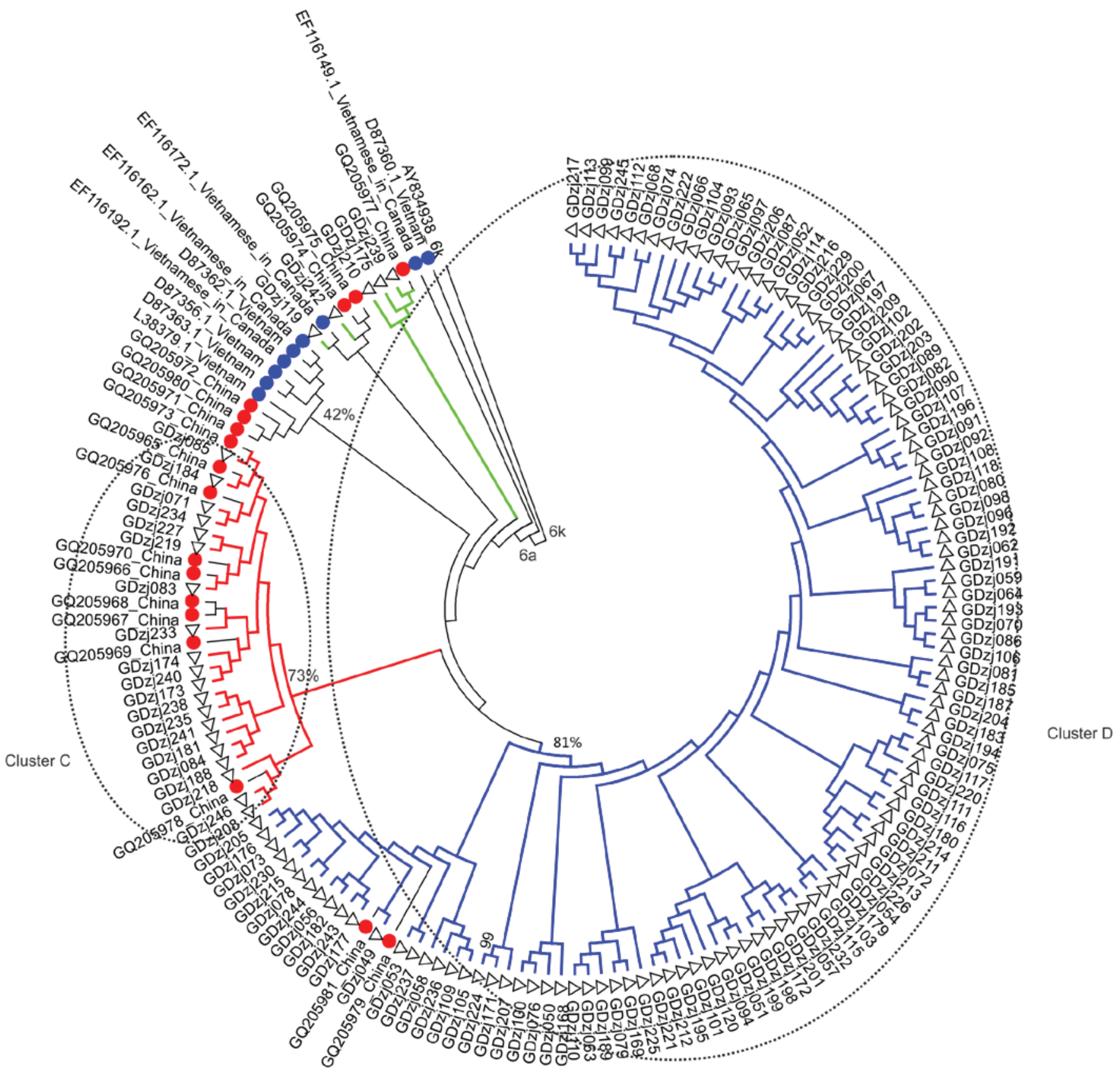

Figure 2. Identification of two clusters of HCV subtype 6a in the survey respondents. The HCV subtype 6a phylogeny was estimated from the NS5B, nonstructural protein 5B region sequences. The HCV subtype $6 \mathrm{k}$ was included as a negative control. Blue circles indicate HCV reference sequences from outside China; red circles indicate HCV reference sequences from other studies in China (origin country and Genbank accession numbers shown). Sequences with triangles are unique to the present study (GenBank accession nos. KJ416703-KJ416924). Sequences connected by blue and red lines, surrounded by black dashed circles are indicative of cluster C ( 20 cases) and cluster D (112 cases). Sequences connected by green lines are indicative of sequences not in cluster $\mathrm{C}$ or $\mathrm{D}$ (5 cases). Bootstrap support values are shown as percentages. $\mathrm{HCV}$, hepatitis $\mathrm{C}$ virus.

subtypes 2a and 6a, differed from previous reports in South China $(18,35)$. This genotypic distribution may have resulted from a specific transmission pattern.

It has been shown that different genotypes are transmitted by different routes. For example, blood transfusion and surgery are more common risk factors for $\mathrm{HCV}$ infection by genotypes 1 and 2. By contrast, blood transfusion and surgery are less common risk factors for infection by genotypes 3 or 6 and lifestyle-associated risk factors, including intravenous drug use, tattoos and piercings, are more common risk factors (32). The subtypes found in the present study were clustered into four homologous groups, and the majority of patients who reported a history of intravenous injection at a local clinic were allocated into these four homologous clusters. The consistency between the epidemiological history and the results of the phylogenetic analysis may indicate a causal association.

As the clinic had closed, it was not possible to confirm intravenous procedures by the healthcare workers. From interviews with former employees of the clinic, it was revealed that intravenous injections were performed using reused glass syringes. As HCV is able to survive outside the body for at least 4 days and the virus is able to survive for weeks in blood 
collected inside a needle or syringe (6), the reuse of glass syringes at this clinic increased the risk of HCV transmission. The reuse of glass syringes has been reported in other provinces of China. In a survey examining esophageal cancer in Anyang (Henan, China) between 2006 and 2008, it was shown that intravenous injection with reusable glass syringes and needles was the primary risk factor for HCV infection (37). Similarly, in Maqiao (Henan, China), $86 \mathrm{HCV}$ infections were found to be caused by intravenous injections with reusable glass syringes at a local clinic (38). Therefore, the outbreak of HCV infections in the present study may have been caused by intravenous injection in the local clinic where glass syringes were reused.

The present study showed the epidemiological characteristic of the outbreak of HCV in Zijin County. The presence of the HCV genotype $6 \mathrm{a}$ in the patients reflected the problem of the increasing spread of HCV genotype $6 \mathrm{a}$ in South China. Although the available evidence is not of sufficient quality to confirm intravenous injection in a local clinic as the causal factor, the present study confirmed the serious health problem associated with reusing contaminated syringes. The present study was limited by the inability to perform the investigation prior to closure of the local clinic to demonstrate the cause of the outbreak. All surveys were performed retrospectively in respondents and the recall bias was unavoidable.

\section{Acknowledgements}

This study was supported by funding from the National Science and Technology Major Project (grant no. 2012ZX10002003) and the Sun Yat-Sen University Clinical Research 5010 Program (grant no. 2010011).

\section{References}

1. Lavanchy D: The global burden of hepatitis C. Liver Int 29 (Suppl 1): S74-S81, 2009.

2. Shepard CW, Finelli L and Alter MJ: Global epidemiology of hepatitis C virus infection. Lancet Infect Dis 5: 558-567, 2005.

3. Sievert W, Altraif I, Razavi HA, Abdo A, Ahmed EA, Alomair A, Amarapurkar D, Chen $\mathrm{CH}$, Dou X, El Khayat H, et al: A systematic review of hepatitis $\mathrm{C}$ virus epidemiology in Asia, Australia and Egypt. Liver Int 31 (Suppl 2): S61-S80, 2011.

4. Esteban JI, Sauleda S and Quer J: The changing epidemiology of hepatitis C virus infection in Europe. J Hepatol 48: 148-162, 2008.

5. Kamal SM and Nasser IA: Hepatitis C genotype 4: What we know and what we don't yet know. Hepatology 47: 1371-1383, 2008.

6. European Association for Study of Liver: EASL Clinical Practice Guidelines: Management of hepatitis C virus infection. J Hepatol 60: 392-420, 2014.

7. Alter MJ: HCV routes of transmission: What goes around comes around. Semin Liver Dis 31: 340-346, 2011

8. van de Laar TJ, Matthews GV, Prins M and Danta M: Acute hepatitis $\mathrm{C}$ in HIV-infected men who have sex with men: An emerging sexually transmitted infection. AIDS 24: 1799-1812, 2010.

9. Guo-Liang Xia, Chong-Bai Liu, Hui-Lin Cao, Sheng-Li Bi, Mei-Yun Zhan, Chong-Ao Su, Jun-Hua Nan and Xiao-Qui Qi: Prevalence of hepatitis B and C virus infections in the general Chinese population. Results from a nationwide cross-sectional seroepidemiologic study of hepatitis A, B, C, D and E virus infections in China, 1992. International Hepatology Communications 5: 62-73, 1996.

10. Shimbo S, Zhang ZW, Gao WP, Hu ZH, Qu JB, Watanabe T, Nakatsuka H, Matsuda-Inokuchi N, Higashikawa K and Ikeda M: Prevalence of hepatitis B and C infection markers among adult women in urban and rural areas in Shaanxi Province, China. Southeast Asian J Trop Med Public Health 29: 263-268, 1998.
11. Tang S: Seroepidemiological study on hepatitis $C$ virus infection among blood donors from various regions in China. Zhonghua Liu Xing Bing Xue Za Zhi 14: 271-274, 1993 (In Chinese).

12. Fu Y, Xia W, Wang Y, Tian L, Pybus OG, Lu L and Nelson K: The seroprevalence of hepatitis C virus (HCV) among 559,890 first-time volunteer blood donors in China reflects regional heterogeneity in HCV prevalence and changes in blood donor recruitment models. Transfusion 50: 1505-1511, 2010.

13. Adams V, Erwin K and Le PV: Public health works: Blood Donation in Urban China. Soc Sci Med 68: 410-418, 2009.

14. Shan H, Wang JX, Ren FR, Zhang YZ, Zhao HY, Gao GJ, Ji Y and Ness PM: Blood banking in China. Lancet 360: 1770-1775, 2002.

15. Shi XL, Ren QH, Zhu ZY, Qu DM, Ji Y, Peng DH and Ni SQ: Hepatitis $\mathrm{C}$ virus infection in blood donors in the People's Republic of China. Transfusion 39: 913, 1999.

16. Xia X, Luo J, Bai J and Yu R: Epidemiology of hepatitis C virus infection among injection drug users in China: Systematic review and meta-analysis. Public Health 122: 990-1003, 2008

17. Dong ZX, Zhou HJ, Wang JH, Xiang XG, Zhuang Y, Guo SM, Gui HL, Zhao GD, Tang WL, Wang H and Xie Q: Distribution of hepatitis $\mathrm{C}$ virus genotypes in Chinese patients with chronic hepatitis C: Correlation with patients' characteristics and clinical parameters. J Dig Dis 13: 564-570, 2012.

18. Gu L, Tong W, Yuan M, Lu T, Li C and Lu L: An increased diversity of $\mathrm{HCV}$ isolates were characterized among 393 patients with liver disease in China representing six genotypes, 12 subtypes, and two novel genotype 6 variants. J Clin Virol 57: 311-317, 2013

19. Cai Q, Zhao Z, Liu Y, Shao X and Gao Z: Comparison of three different HCV genotyping methods: Core, NS5B sequence analysis and line probe assay. Int J Mol Med 31: 347-352, 2013.

20. Chenna R, Sugawara H, Koike T, Lopez R, Gibson TJ, Higgins DG and Thompson JD: Multiple sequence alignment with Clustal series of programs. Nucleic Acids Res 31: 3497-3500, 2003.

21. Smith DB, Bukh J, Kuiken C, Muerhoff AS, Rice CM, Stapleton JT and Simmonds P: Expanded classification of hepatitis $\mathrm{C}$ virus into 7 genotypes and 67 subtypes: Updated criteria and genotype assignment web resource. Hepatology 59: 318-327, 2014.

22. Posada D: jModelTest: Phylogenetic model averaging. Mol Biol Evol 25: 1253-1256, 2008

23. Aho K, Derryberry D and Peterson T: Model selection for ecologists: The worldviews of AIC and BIC. Eclogy 95: 631-636, 2014.

24. Guindon S and Gascuel O: A Simple, fast, and accurate algorithm to estimate large phylogenies by maximum likelihood. Syst Biol 52: 696-704, 2003.

25. Gao X, Cui Q, Shi X, Su J, Peng Z, Chen X, Lei N, Ding K, Wang L, Yu R and Wang N: Prevalence and trend of hepatitis $\mathrm{C}$ virus infection among blood donors in Chinese mainland: A systematic review and meta-analysis. BMC Infect Dis 11: 88, 2011.

26. Cui Y and Jia J: Update on epidemiology of hepatitis B and C in China. J Gastroenterol Hepatol 28 (Suppl): S7-S10, 2013.

27. Alter MJ, Kruszon-Moran D, Nainan OV, McQuillan GM, Gao F, Moyer LA, Kaslow RA and Margolis HS: The prevalence of hepatitis C virus infection in the United States 1998 through 1994. N Eng J Med 341: 556-562, 1999.

28. Arrese M, Riquelme A and Soza A: Insulin resistance, hepatic steatosis and hepatitis $\mathrm{C}$ : A complex relationship with relevant clinical implications. Ann Hepatol 9 (Suppl): S112-S118, 2010.

29. Lee MH, Yang HI, Yuan Y, L'Italien G and Chen CJ: Epidemiology and natural history of hepatitis $\mathrm{C}$ virus infection. World J Gastroenterol 20: 9270-9280, 2014.

30. Knapp S, Warshow U, Ho KM, Hegazy D, Little AM, Fowell A, Alexander G, Thursz M, Cramp M and Khakoo SI: A polymorphism in IL28B distinguishes exposed, uninfected individuals from spontaneous resolvers of HCV infection. Gastroenterology 141: 320-325, 2011.

31. Liu Y, Ma H, Chen S, Wang J, Liu G, Xu M, Ke L and He M: Interleukin-28B genetic variations and spontaneous clearance of hepatitis $\mathrm{C}$ antibody-positive blood donors in China. Transfusion 53: 2498-2504, 2013.

32. Rao HY, Sun DG, Jiang D, Yang RF, Guo F, Wang JH, Liu F, Zhang HY, Zhang HH, Du SC, et al: IL28B genetic variants and gender are associated with spontaneous clearance of hepatitis $\mathrm{C}$ virus infection. J Viral Hepat: 19 173-181, 2012.

33. Simmonds P, Bukh J, Combet C, Deléage G, Enomoto N, Feinstone S, Halfon P, Inchauspé G, Kuiken C, Maertens G, et al: Consensus proposals for a unified system of nomenclature of hepatitis C virus genotypes. Hepatology 42: 962-973, 2005. 
34. Robertson B, Myers G, Howard C, Brettin T, Bukh J, Gaschen B, Gojobori T, Maertens G, Mizokami M, Nainan O, et al: Classification, nomenclature, and database development for hepatitis $\mathrm{C}$ virus (HCV) and related viruses: Proposals for standardization. International committee on virus taxonomy. Arch Virol 143: 2493-2503, 1998.

35. Fu Y, Qin W, Cao H, Xu R, Tan Y, Lu T, Wang H, Tong W, Rong X, Li G, et al: HCV 6a prevalence in Guangdong province had the origin from Vietnam and recent dissemination to other regions of China: Phylogeographic analyses PLoS One 7: e28006, 2012.
36. Fu Y, Wang Y, Xia W, Pybus OG, Qin W, Lu L and Nelson K: New trends of $\mathrm{HCV}$ infection in China revealed by genetic analysis of viral sequences determined from first-time volunteer blood donors. J Viral Hepat 18: 42-52, 2011.

37. Liu F, Chen K, He Z, Ning T, Pan Y, Cai H and Ke Y: Hepatitis C seroprevalence and associated risk factors, Anyang, China. Emerg Infect Dis 15: 1819-1822, 2009.

38. Guo YH, Fan JX, Wang Z, Sun DY, Wang HF, Li ML, Liu J, Cui WG, Liu GH and Guo WS: Sero-prevalence and associated risk factors on hepatitis $\mathrm{C}$ in Maqiao township, Henan province of China. Zhonghua Liu Xing Bing Xue Za Zhi 33: 722-725, 2012 (In Chinese). 